\title{
ARTIGO \\ DOS LICEUS AOS INSTITUTOS FEDERAIS: 110 ANOS DE HISTÓRIA DA REDE FEDERAL $^{1}$
}

\section{Ana Kelly Arantes ${ }^{2}$ \\ Márcia Helena Batista Corrêa da Costa}

\section{RESUMO}

Este artigo tem por objetivo fazer um percurso histórico, demonstrando o caminho do ensino técnico no Brasil ao longo dos diversos momentos e governos do país, alinhando as legislações pertinentes e ações legais desta modalidade. Iniciou-se este percurso ainda no Brasil escravocrata, passando pelos Liceus, primeiras instituições de educação técnica de nível federal, até a criação dos Institutos Federais, em 2008, quando, por meio da criação destes, na primeira vez na história do Brasil, tem-se a pretensão de uma educação técnica que visa a uma formação integral, que supere as marcas históricas trazidas pela modalidade, como uma educação fragmentada, puramente tecnicista e voltada simplesmente a atender interesses do mercado, tendo sido preterida ao lugar de uma educação menor. Destacaram-se, portanto, os Institutos Federais, que compõem a Rede Federal de Educação Tecnológica, como a grande mudança de perspectiva com relação à educação técnica e profissional. Fez-se um breve panorama do desenvolvimento desta Rede nos seus 10 anos de história, e, por último, um recorte no Instituto Federal de Educação, Ciência e Tecnologia de Minas Gerais (IFMG), demonstrando os campi criados e seu desenvolvimento. Para a realização do artigo, empregou-se metodologia de cunho qualitativo e, uma análise documental, tendo por base documentos oficiais e legislações pertinentes a cada momento histórico percorrido. Foi produzida, também, uma revisão de literatura, recorrendo aos diversos autores que se debruçam sob o tema. Os resultados demonstram que a educação, como um projeto em disputa, e mais especificamente a educação profissional, sofre os atravessamentos tanto no seu cotidiano como em âmbitos legais, sendo que o artigo vem apontando historicamente estes desdobramentos.

Palavras-chave: Educação técnica e profissional. Histórico. Institutos Federais.

\section{INTRODUÇÃO}

O mês de dezembro de 2018 datou os dez anos de criação dos Institutos Federais, instituídos a partir da Lei $\mathrm{N}^{\circ}$ 11.892, de 29 de dezembro de 2008. Já no apagar das luzes desse ano, iniciou-se a implantação de uma Rede que visava, entre outros horizontes: democratizar, interiorizar, ampliar e oferecer educação pública em diferentes modalidades de ensino, em uma só instituição.

\footnotetext{
${ }^{1}$ Como citar este artigo: ARANTES, Ana Kelly; COSTA, Márcia Helena Batista Corrêa. Dos Liceus aos Institutos Federais: 110 anos de história da rede federal. ForScience: revista científica do IFMG, Formiga, v. 7 , n. 2, e00697, jul./dez. 2019. DOI: 10.29069/forscience.2019v7n2.e697.
}

\footnotetext{
${ }^{2}$ Autor para correspondência: Ana Kelly Arantes; e-mail: anakarantes@gmail.com.
} 
Nestes dez anos, é possível afirmar que a Rede Federal de Educação Profissional, Científica e Tecnológica vem se consolidando e se tornando uma marca forte no âmbito da educação nacional, tendo como "carro-chefe" e diferencial o ensino médio. Até mesmo a legislação vem garantindo que 50\% do número de vagas sejam resguardadas para esta modalidade, desta tentativa recente de uma educação com bases integradas, o presente artigo tem por objetivo desenhar historicamente a educação técnica no Brasil, que foi, durante anos, rebaixada e subjugada a um patamar menor, para atender puramente aos interesses do mercado preferencialmente nos currículos integrados.

A despeito, seja para formar mão de obra com um saber simplificado, seja como ação conciliadora do Estado, na busca por tirar das ruas os filhos dos desvalidos econômica e socialmente.

No percurso histórico desenvolvido neste texto, tentou-se demonstrar o caminho do ensino técnico no Brasil ao longo dos diversos momentos e governos do país, alinhando as legislações pertinentes e ações legais voltadas para este fim. Iniciou-se este percurso nos Liceus, primeiras Instituições de Educação Técnica, até a criação dos Institutos Federais.

Segundo Saviani (2007), os fundamentos ontológicos e históricos da relação trabalho e educação são: "trabalho e educação são atividades especificamente humanas. Isto significa que, rigorosamente falando, apenas o ser humano trabalha e educa" (SAVIANI, 2007 p. 152). Segundo o autor, a essência do homem é produzida por ele mesmo, uma vez que esta é o trabalho. Então, se ela não é uma dádiva natural, se é produzida pelo homem, ele precisa aprender a ser, aprender a produzir sua própria existência. Portanto, a educação coincide com a origem do próprio homem. $\mathrm{O}$ autor destaca, ainda, que a educação profissionalizante não deve se resumir a mero adestramento em determinada habilidade, pois, quando baseada no conceito de politécnica, ou seja, “[...] especialização como domínio dos fundamentos científicos das diferentes técnicas utilizadas na produção moderna.” (SAVIANI, 2007, p. 161), propõe o conhecimento das habilidades aliado ao processo produtivo como um todo.

A metodologia empregada neste trabalho consistiu em uma pesquisa documental nos documentos oficiais, como históricos, missão institucional, legislações. Além de revisão de literatura nos artigos e autores que se debruçaram sobre o tema.

O uso de documentos em pesquisa deve ser apreciado e valorizado. A riqueza de informações que deles podemos extrair e resgatar justifica o seu uso em várias áreas das Ciências Humanas e Sociais porque possibilita ampliar o entendimento de objetos cuja compreensão necessita de contextualização histórica e sociocultural (SÁ-SILVA; ALMEIDA; GUINDANI, 2009, p. 2). 
Utilizando-se, portanto, destes arcabouços metodológicos ousou-se ir "costurando" os caminhos do ensino técnico, profissional e seu desenrolar ao longo da história educacional brasileira.

\section{DESENVOLVIMENTO}

Nesta seção, percorrer-se-ão os momentos históricos da educação profissional e do ensino técnico no Brasil, lançando mão das diversas legislações pertinentes, buscando-se o movimento do todo e em parte, sempre se alinhando o contexto político, econômico e social e seus reflexos no tema do artigo: a educação profissional.

Inicia-se este percurso ainda no contexto de Brasil escravocrata, destacando-se os Liceus como as primeiras escolas de educação profissional de iniciativa de um governo federal, chegando-se até as investidas mais recentes no que tange à modalidade de educação em estudo, já no século XXI. Passeia-se brevemente pela criação e expansão dos Institutos Federais e Rede Federal; posteriormente, há um breve recorte no Instituto Federal de Educação, Ciência e Tecnologia de Minas Gerais (IFMG).

Discutir a história da educação no Brasil e suas respectivas legislações, segundo Ramos (2014), deve vir sempre à luz do desenvolvimento econômico brasileiro, e, por conseguinte dos projetos societários em disputa, que embrenham as tomadas das decisões e recaem fortemente sobre os caminhos e tendências das políticas.

\subsection{Ensino técnico: um percurso histórico}

Ao se pensar uma formação integrada ou integral, tem-se no horizonte que o ensino se divide em duas esferas: a propedêutica, voltada para saber pensar, a formação intelectual; e uma segunda, direcionada para a operacionalização, onde se insere o ensino técnico profissional, destinado a formar a massa produtiva do capitalismo. A autora destaca que o desenvolvimento dessa modalidade de ensino, no Brasil, se articula fortemente com interesses específicos, relacionados à implantação e à reprodução do capitalismo (BIAGINI, 2001).

Na mesma direção, Kuenzer (1992) explica que a educação articulada ao trabalho, teve sua marca na capacitação de parcelas mais pobres e até marginalizadas da população, preparadas para atuarem nos postos de trabalho de baixo e médio escalão. Segundo Cunha (2000) existe, no País, uma marca estigmatizante do trabalho manual, pelo menos daqueles 
considerados menores, ou seja, marginalizados, menosprezados, relacionada ao ofício dos escravos. Portanto, não se vincular a este tipo de atividade, indicava, inclusive, quem se era, e qual suas raízes; não é de estranhar, que se afastarem destes postos, dizia da própria condição daquele sujeito.

[...] a rejeição era menos diante do trabalho manual do que à condição social daqueles que o exerciam - os escravos e seus descendentes - que não tinham o mesmo sinal étnico da liberdade e da dignidade - a cor da pele (CUNHA, 2000, p. 90).

O autor faz uma ressalva importante - que nem todos os trabalhos manuais eram desprezados, pois havia aqueles que os brancos livres tomavam para si, e exerciam uma pressão de branqueamento, apoiada, inclusive, pelas forças institucionais, como as câmaras municipais, que, se não impediam os negros de ocuparem certos postos, dificultavam substancialmente. Portanto, Cunha (2000) destaca que não se trata apenas do desprezo pelo trabalho manual, mas por aqueles postos "denegridos". Restava, então, a alternativa de preparar os jovens e adolescentes, os que não tinham muitas escolhas ou resistências.

Existiram experiências pioneiras que se destinavam a ensinar algum ofício, como o Colégio de Fabricas, em 1809, no Rio de Janeiro, criado para abrigar os órfãos trazidos de Portugal, junto com a Família Real e sua comitiva, onde se ensinavam diversos ofícios. Cunha (2000) afirma que esta não fora a primeira experiência de ensino profissional no Brasil, mas foi a que mais serviu de exemplo para, mais tarde, os Estados Provincianos criarem as suas Casas de Educandos Artífices (1840-1856).

Já no período do Império, em meados do século XIX, a produção das manufaturas no Brasil cresce, exigindo que a sociedade civil se organizasse para suprir esta carência. Neste cenário, os primeiros Liceus chegam ao Brasil, financiados por sócios, cotistas, benfeitores, e alguns investimentos governamentais. Cunha (2000) afirma que o mais importante liceu foi o do Rio de Janeiro (1858). Os Liceus de Artes e Ofícios dispunham de cursos abertos, proibidos apenas para os escravos; mas, como os recursos eram escassos, não possuíam oficinas, nem laboratórios práticos, apenas salas de aula.

No período do Império, tanto as iniciativas do Estado, voltadas para o ensino de ofícios, quanto as das sociedades civis eram legitimadas por ideologias que pretendiam: a) imprimir a motivação para o trabalho; b) evitar o desenvolvimento de ideias contrárias à ordem política, de modo a não se repetirem no Brasil as agitações que ocorriam na Europa; c) propiciar a instalação de fábricas que se beneficiariam da existência de uma oferta de força de trabalho qualificada, motivada e ordeira; e d) favorecer próprios trabalhadores, que passariam a receber 
salários mais elevados, na medida dos ganhos de qualificação (CUNHA, 2000, p. 92).

Segundo Neves (2008), a despeito dessas tentativas embrionárias de educação profissional no Brasil, somente em 1909, surge a primeira iniciativa governamental em nível Federal, com a fundação das Escolas de Aprendizes e Artífices.

Naquele ano, foram criadas as primeiras Escolas de Aprendizes, no governo de Nilo Peçanha, com o propósito de habilitar os filhos dos desfavorecidos da fortuna para o trabalho, afastando os dos vícios, dos crimes e da ociosidade. Essas escolas, portanto, serviam para minimizar os efeitos da profunda desigualdade social da época - "em outras palavras, nas escolas de aprendizes, mediante o doutrinamento disciplinar, teve-se a pretensão de preparar aqueles jovens para a sua inserção, de forma não conflitante, no mundo da produção" (BIANGINI, 2001, p. 3).

Os primeiros esforços de ensino técnico estiveram intimamente ligados às ações de filantropia do próprio Estado e de Instituições que também se esforçaram nesse sentido, tais como igrejas e empresas privadas. Essas ações possuíam um caráter moralizador da pobreza, como se apresenta no trecho da lei:

\footnotetext{
O Presidente da Republica dos Estados Unidos do Brazil, em execução da Lei N. 1.606, de 29 de dezembro de 1906:

Considerando: que o aumento constante da população das cidades exige que se facilite às classes proletárias os meios de vencer as dificuldades sempre crescentes da luta pela existência: que para isso se torna necessário não só habilitar os filhos dos desfavorecidos da fortuna com o indispensável preparo técnico e intelectual, como faze-los adquirir hábitos de trabalho profícuo, que os afastará da ociosidade ignorante, escola do vício e do crime; que é um dos primeiros deveres do Governo da República formar cidadãos uteis à Nação (BRASIL, 1909, não paginado).
}

Verifica-se que, em paralelo às iniciativas federais, existiam as ações em nível estadual. No entanto, é importante destacar o papel da Igreja nessa modalidade de formação para o trabalho simples, que tinha, antes de tudo, o objetivo de moralizar a pobreza, e integrar as novas classes sociais, que emergiam com o processo de urbanização resultante da abolição da escravatura, em um novo cenário de industrialização. A Igreja Católica, principalmente, chegou a ter 14 escolas destinadas a esse fim, porém totalmente descoladas de um sistema formal de ensino (NEVES, 2008).

No entanto, foi a partir dos anos de 1940 que a preocupação em formar mão-de-obra para a indústria se intensificou, tanto que em 1942 foi aprovada a Lei Orgânica do Ensino Industrial, (BRASIL, 1942a) a partir da qual se criou o Serviço Nacional de Aprendizagem Industrial (SENAI), e, posteriormente, em 1946, o Serviço Nacional de Aprendizagem 
Comercial (SENAC), os dois da iniciativa privada. Já o ensino industrial da rede federal foi formalizado pelo Decreto n. ${ }^{\circ}$ 4127, de 25 de fevereiro de 1942 (BRASIL, 1942b; NEVES, 2008).

Em 1942, ocorreu a Reforma Capanema, que passou a considerar e formalizar o ensino profissionalizante em nível médio. O ingresso nas escolas industriais passou a depender de exames de admissão, e os cursos foram divididos em dois níveis, o primeiro correspondia aos cursos básicos industriais, e o segundo, aos cursos técnicos industriais com três anos de duração, com estágio na indústria. Porém, essa medida serviu para intensificar ainda mais a distância entre o ensino acadêmico e o técnico, criando-se uma divisão de sistema educacional: de um lado, a educação intelectualista científica, organizada a partir de conceitos rígidos, seletivos, capazes de levar seus egressos ao ensino superior; do outro, o ensino profissional. Evidencia-se uma estrutura destinada às camadas populares, em que, diferentemente do outro modelo, seus estudantes não podiam acessar cursos superiores, somente aqueles equivalentes aos cursos técnicos (BIANGINI, 2001).

Neves (2008) revela que, até mesmo dentro do ensino técnico industrial, havia uma dicotomia, - as escolas que eram destinadas ao ensino médio e tecnológico, e as profissionalizantes, que simplesmente preparavam o sujeito para um determinado ofício, oferecendo uma formação básica, um treinamento.

As autoras supramencionadas convergem análises ao afirmar que foi a passagem da economia brasileira, de predominantemente agrária para a diversificação das bases da economia, bem como a industrialização, que mudou as relações do Estado com todas as esferas da sociedade, aumentando sua cobertura e proteção a fim de uma conformação das classes sociais. Segundo Romanelli (1983), nas décadas de 1950 e 1960, a taxa de alfabetização cresceu $1,2 \%$ ao ano, bem acima da taxa de $0,5 \%$ verificada ao longo da década anterior.

Vale destacar o papel do governo de Juscelino Kubitschek (1956-1961) no amplo desenvolvimento, com interferências do capital estrangeiro, na economia brasileira e a necessidade de modernizar o país, investindo na formação técnica. Nesse contexto, o ensino técnico ganhou dimensão de prioridade por parte do Estado, porém ainda voltado para a população pobre, sendo que o ensino propedêutico ainda era destinado aos abastados, que chegariam à universidade.

Como o ensino técnico era prioridade, criou-se a Lei n. ${ }^{\circ} 3552$, de 16 de fevereiro de 1959 (BRASIL, 1959). As escolas ligadas ao Ministério da Educação e Cultura constituíram, por meio desta lei, autonomia didática, administrativa, técnica e financeira. Por meio de um 
Conselho, instituído Conselho de Professores, presidido pelo diretor da Instituição, passou-se a ter autonomia de deliberar sobre o orçamento da escola, organização dos cursos, métodos de avaliação, podendo, inclusive, realizar contratação do corpo docente e administrativo, respeitando até $50 \%$ do orçamento, para o primeiro, e $10 \%$ para o segundo. Ao longo do texto da lei, é possível identificar fortes ligações com as aspirações do mercado, até com o contexto desenvolvimentista da época, como, por exemplo: era permitido o recebimento de encomendas de terceiros, mediante pagamento, e também receber financiamentos externos para compor o orçamento anual escolar.

Todavia, a lei supracitada teve curta duração, sendo substituída posteriormente pela Lei de Diretrizes e Bases de 1961, que “[...] evidenciou a primeira tentativa de articulação dos dois sistemas de ensino, a partir da equivalência plena entre os cursos propedêuticos e os profissionalizantes" (BRASIL, 1961; BIANGINI, 2001, p. 7). A autonomia oferecida por essa lei fez com que as escolas industriais e técnicas fossem elevadas ao status de autarquias, chamadas de Escolas Técnicas Federais.

Com a ditadura militar, iniciada em 1964, todas as esferas da vida social foram alteradas, e tais mudanças foram sustentadas pela burguesia nacional, que necessitava garantir sua hegemonia. Mais uma vez, a educação profissionalizante se encarregava de fornecer mão de obra ao mercado, e o ensino técnico servia para as fábricas e os interesses capitalistas manterem a ordem nas linhas de produção (BIANGINI, 2001).

O País, ao longo de décadas, passou por significativa modernização e por mudanças profundas nos processos de trabalho e produção. Um conjunto de termos mais técnicos voltados ao saber científico e tecnológico, que adentrava o cotidiano das indústrias, precisavam ser desvelado e culturalmente apreendido. Esse quadro ia além dos conteúdos ministrados pelas escolas até então, sendo que a educação, como parte constitutiva da vida social, acompanhou tais mudanças, mesmo que, muitas vezes, a passos lentos. Os níveis de escolaridade obrigatórios foram se estendendo ao longo do século $\mathrm{XX}$, de quatro anos da escolarização primária para oito anos, que compreendiam o ensino do $1^{\circ}$ grau, tornando-se obrigatório pela Lei n ${ }^{\circ}$ 5692, de 11 de agosto de 1971 (BRASIL, 1971; NEVES, 2008).

A Lei 5692/71 estabeleceu o objetivo geral do ensino em $1^{\circ}$ e $2^{\circ}$ graus, ou seja, promover o desenvolvimento de potencialidades como elemento de auto-realização, aptidões para o trabalho e exercício da cidadania. Porém, era específica a qualificação para o trabalho em cada nível: o $1^{\circ}$ seria voltado para sondagens de aptidões e preparação para o trabalho; já o $2^{\circ}$ ficaria a cargo da habilitação profissional (BRASIL, 1971; BIANGINI, 2001). 
Cury; Tambini; Salgado (1982) aponta que a referida lei apresenta uma mudança de paradigma na relação escola e trabalho, sem muitos contornos definidos no começo, mas que, influenciada pelo próprio contexto econômico, essa relação se consolidou muito mais na perspectiva escola - mercado de trabalho, escola para empregabilidade. Foram sentidas, naquele momento, algumas dificuldades de implementação do novo modelo de ensino em $2^{\circ}$ grau profissionalizante, pois havia uma tentativa de unificação e universalização do modelo por todo o País, no anseio de uma educação equânime. Observou-se que faltaram discussões com os profissionais envolvidos, tendo sido desconsideradas as estruturas e as vocações de cada Instituição, limando da operacionalização o grande avanço que a lei trazia: "a ideia de que a formação integral do adolescente inclui necessariamente algum tipo de relação com o mundo do trabalho" (CURY; TAMBINI; SALGADO, 1982, p.56). Entende-se, dessa forma, trabalho como atividade transformadora do homem sobre a natureza, com o intuito de promoção da existência e sobrevivência, como parte constitutiva do ser social, e não essa visão reducionista e submissa aos interesses do mercado.

Porém, segundo Neves (2008), a referida lei criou um novo dualismo. Enquanto a Igreja Católica e os estabelecimentos de ensino particulares continuaram oferecendo ensino propedêutico, voltado para as camadas superiores da população, as escolas públicas de $2^{\circ}$ grau mandavam seus egressos para cursos superiores menos valorizados, ou seja, cursos paralelos e principalmente voltados para a preparação demandada pelo mercado de trabalho.

Biangini (2001) mostra que, na década de 1970, quando se estabeleceu a ditadura no Brasil, os governos militares investiram em um desenvolvimento acelerado, além de centralizar o poder e criar uma estrutura tecnocrática - estratégias voltadas para mostrar um Estado forte e poderoso, pronto para desenvolver o país do ponto de vista econômico e social. Foi também nesse contexto que o País adotou medidas que favoreceram as multinacionais, acreditando-se que tudo isso elevaria o Brasil ao patamar de nação desenvolvida de primeiro mundo.

Pode-se afirmar, mais uma vez, que a educação foi usada como formadora de mão de obra para o mercado, tal como citado anteriormente. O modelo capitalista implantado ampliava-se a passos largos, exigindo a qualificação dos trabalhadores. "O propósito de estabelecer uma concordância entre uma proposta pedagógica de educação e o modelo de desenvolvimento pretendido pelo governo fez com que a essência da educação fosse concebida de forma fragmentada" (BIANGINI, 2001, p. 9).

Tanto Biangini (2001) como Neves (2008) afirmam que o caráter elitista da educação brasileira não foi superado ao longo das transformações legais ocorridas no campo da 
educação. Mesmo com a já citada lei 5692/71 em vigor, Biangini (2001) afirma que apenas as escolas que já tinham cursos profissionalizantes continuaram a ministrá-los; as escolas das classes abastadas da população investiam no ensino propedêutico e na preparação para o vestibular. E as escolas públicas, por falta de recursos e estrutura, não faziam nem uma coisa nem outra com qualidade, prática e teoria continuavam separadas, assim como educação e trabalho.

Nesse contexto, vale destacar a trajetória das escolas técnicas federais, que começaram a oferecer cursos profissionais superiores de curta duração, permitidos pelo Decreto-Lei 547, de 18 de abril de 1969 (BRASIL, 1996). Foi a partir de então que o ensino tecnológico adentrou os cursos superiores, sendo oferecidos em $2^{\circ}$ e $3^{\circ}$ graus, apesar de criar uma hierarquização nessa modalidade, embora tenha se tornado uma nova alternativa no âmbito da formação técnica. Esse processo se amplia quando as três escolas técnicas em Minas Gerais, Rio de Janeiro e Paraná, foram elevadas a Centro Federal de Educação Tecnológica -CEFET por meio da Lei $\mathrm{n}^{\circ}$ 6.545, de 30 de junho de 1978. Em 1982, o Decreto N. 87.310 definiu que essas Instituições poderiam, dentre outras coisas, oferecer cursos de graduação, pósgraduação, ensino técnico integrado ao médio e pesquisas na área industrial (BRASIL, 1982). Essas eram as escolas que se destacavam pela qualidade, conseguindo alinhar o ensino para o trabalho e o ensino propedêutico, sendo que as outras continuavam separadas e, muitas vezes, esta segregação era determinada pela classe social.

O Brasil começa a sentir a crise, que pode ser observada em nível mundial, advinda da falência do modelo econômico de desenvolvimento acelerado, no fim dos anos 1970 e 1980 a última, inclusive, ficou conhecida como a "década perdida", do ponto de vista econômico e social. Os anos 1980 também marcaram o fim dos governos militares, que, a esta altura, sofriam duras pressões da sociedade, principalmente de segmentos da classe média e da burguesia nacional, que exigiam participação nos processos decisórios do País (BIANGINI, 2001).

É também na transição da década de 1970 para a de 1980 que o sistema capitalista reage, principalmente à Crise do Petróleo, que coloca em cheque as políticas de bem - estar social, adentrando, no cenário, o neoliberalismo, sendo a Inglaterra, chefiada por Margaret Thatcher, a precursora da reinvenção capitalista que, durante a década, chegaria em várias nações mundo afora, não ficando o Brasil fora desta investida. Essa nova roupagem não atingiu somente a economia, mas as novas regras recaíram fortemente em todos os níveis da vida social, e, como não poderia deixar de ser, a educação sofreu fortes impactos (MARTINS, 2000). 
[...] Assim como o direito de propriedade passa a submeter todos os direitos humanos fundamentais, a educação passa a ser mais um dos muitos produtos oferecidos, adquiridos graças ao despendimento de recursos financeiros, perdendo seu caráter público universal e passando a cumprir outras determinações, impostas pelo mercado (MARTINS, 2000, p. 63).

Nesse contexto, o ensino técnico estruturou-se a partir da atuação em três níveis: o industrial - para atender à demanda de mão de obra do mercado; o tecnológico - responsável por desenvolver, adaptar e assistir o ramo industrial no uso da tecnologia; o social - que " [...] estabelecia-se pela meta de promover a valorização do técnico por meio da qualidade de seu processo de formação e da inserção de seus egressos no mercado, como técnicos" (BIANGINI, 2001, p. 11). Nessa década, as escolas que ofereciam cursos técnicos (quase exclusivamente escolas federais) na modalidade integrado ao ensino médio, ou os subsequentes, começaram a ser vistas como uma boa alternativa de formação por estudantes de classe média, passando, então, a serem consideradas escolas públicas de qualidade. Podese atribuir esta mudança de concepção quanto às escolas técnicas, a partir das próprias ideias em que estavam se fixando os processos educacionais, a escola como ponte para o mercado, formação para empregabilidade, sendo, portanto, as escolas técnicas o melhor cenário para o momento. Porém, mais uma vez, os estudantes oriundos dos estratos mais baixos não se apresentavam em condições de competir nos exames de seleção para disputar entrada nessas instituições.

O País, na segunda metade da década de 1980, passou por um processo de democratização, culminando na Constituição de 1988, que, em seu artigo 205, determina a educação como direito de todos e dever do Estado. Mais tarde, a Lei de Diretrizes e Bases da Educação (LDB)/1996, tratou mais especificamente o ensino técnico e definiu alguns balizadores para essa modalidade de ensino (BRASIL, 1996).

A nova LDB determina dois níveis de ensino: a educação básica e a educação superior, trazendo, em seu Título V - Dos Níveis e das Modalidades da Educação e do Ensino - uma terceira via entre a educação básica e superior, a educação profissional, “[...] uma modalidade de educação escolar voltada para conduzir o trabalhador ao desenvolvimento de aptidões para a vida produtiva, por meio de cursos de formação inicial e continuada" (NEVES, 2008. p. 60).

Segundo Neves (2008), no início dos anos 1990, a educação escolar brasileira foi redefinindo seus objetivos e finalidades, absorvendo, para formação, premissas da "qualidade total", em alta no mercado, a fim de aumentar a produtividade e a competitividade não só nas empresas, mas também no desempenho dos trabalhadores, sendo demandado: 
“[...]a formação do trabalhador "autoqualificado" para a produtividade, com o seguinte perfil básico: ser responsável, participativo, atento às inovações do processo produtivo, criativo e capaz de alavancar a produtividade” (BIANGINI, 2001, p. 13).

Foi nesta década que o projeto neoliberal, iniciado na década de 1980, de fato se consolidou. Os organismos internacionais, como Banco Mundial, BIRD, voltaram a ditar novas regras ao sistema educacional dos países periféricos, incutindo uma lógica de mercado ainda mais severa que as sentidas até aquele momento (MARTINS, 2000).

Frigotto (2018) afirma que, até então, por mais que os organismos internacionais já vinham adentrando os meandros das políticas sociais, no Brasil, foi com a eleição de Fernando Henrique Cardoso (1995-2002), que, de fato, as portas foram abertas. Segundo ele, havia dois projetos educacionais em disputa no campo da educação tecnológica: um que buscava consolidar uma educação politécnica, omnilateral, ou seja, voltada à formação integral, para o mundo do trabalho; e outra que se firmava nos já citados valores, que, no momento, estavam em voga, formação polivalente, tecnicista, baseada no desenvolvimento de competências individuais, para atender aos interesses do mercado. Frigotto (2018) reafirma que foi neste cenário que o pêndulo inclinou-se fortemente para a segunda perspectiva, com vieses conservadores e tecnicistas, e o neoliberalismo tornou-se hegemônico.

A formação para o trabalho, tanto em seu formato simples quanto complexo, foi direcionada para que o aumento da produção e do consumo fosse disseminado por meio do conhecimento e da apropriação de novos valores, seja no plano simbólico ou material (NEVES, 2008). Os novos valores provinham da ideia de um Estado mínimo, que não mais se voltava ao bem-estar de seus cidadãos, mas para atender aos interesses do mercado.

Ramos (2014) esclarece que, com a eleição de um presidente que representava todo o anseio da nova estruturação produtiva, a Secretaria de Educação Média e Tecnológica do Ministério da Educação (SEMTEC), já preocupada em alinhar sua pasta às novas aspirações, caminhava em dois sentidos: 1) um novo modelo pedagógico para as escolas subordinadas à Secretaria e, 2) instituir o Sistema Nacional de Educação Tecnológica, transformando todas as escolas em Centro Federais de Educação Tecnológica (CEFET). Neste cenário, foi promulgada a lei N. 8.948, de 1994, que previu, no âmbito legal, estas medidas. A autora, dialeticamente, aponta as duas faces desta ação, pois tanto havia componentes conservadores quanto a tentativa de fortalecimento da educação técnica por meio da criação de um sistema -a cefetização - pois as escolas vinham sofrendo constantes ameaças, tanto de serem transferidas aos governos estaduais, como ao Sistema $\mathrm{S}$, além de serem privatizadas. Sabe-se que as forças conservadoras vinham ganhando amplamente esta queda de braço, e não foi por esta Lei que 
as escolas foram elevadas a CEFETs, por falta de regulamentação. Mais tarde, em 1997, cada escola teve uma portaria única para que esta transformação se efetivasse.

Nos anos 2000, é necessário destacar dois movimentos importantes na reformulação da educação profissional: a recuperação do ensino tecnológico de nível médio e o esforço em integrar legalmente essa modalidade ao ensino superior. E a grande virada com relação a essa modalidade foi a criação dos Institutos Federais. Essas novas estruturas são, em parte, oriundas dos CEFETs, de Escolas Agrotécnicas e de Escolas Técnicas ligadas às universidades federais.

\subsection{Institutos Federais - panorama dos seus 10 anos de história}

Essa empreitada teve início em 2005, com a derrubada da já citada Lei no 8.948, de 8 de dezembro de 1994, que, entre outras deliberações, trazia a proibição de abertura de novas unidades de ensino profissional no Brasil. Tal lei foi substituída pela Lei $\mathrm{n}^{\circ} 11.195$, de 18 de novembro de 2005.

De acordo com as informações do Ministério da Educação (MEC), constantes no site oficial, naquele momento, a ampliação da Rede foi pensada em três fases: a fase I, que se iniciou logo após a promulgação da Lei $n^{\circ} 11.195$, com a previsão da construção de Escolas em locais que ainda não tinham unidades, como Acre, Amapá, Mato Grosso do Sul, além das periferias e municípios interioranos, os quais ainda se tratavam de CEFETs, Escolas Agrotécnicas e unidades ligadas a estas.

A expansão II, iniciada em 2007, estabeleceu como meta a criação de 150 escolas de educação técnica e profissional, distribuídas em 26 Estados. Esse processo culminou na criação dos Institutos Federais, através da Lei no 11.892, de 29 de dezembro de 2008, no governo do Partido dos Trabalhadores. Em sua maioria, nascem dos já instituídos CEFETEs e Escolas Agrotécnicas, que se aglutinam para formar os novos arranjos institucionais. Esses Institutos caracterizam-se por abarcar, na mesma Instituição, o ensino que vai desde a formação de nível médio integrado ao técnico até cursos de pós-graduação (MEC, 2018).

Os Institutos Federais trazem, em seus aspectos legais, novas finalidades e características para seu ensino, como o alinhamento de formação para cidadania e formação para o mundo do trabalho:

I - ofertar educação profissional e tecnológica, em todos os seus níveis e modalidades, formando e qualificando cidadãos com vistas na atuação profissional 
nos diversos setores da economia, com ênfase no desenvolvimento socioeconômico local, regional e nacional;

Art. $7^{\circ}$ - Observadas as finalidades e características definidas no art. $6^{\circ}$ desta Lei, são objetivos dos Institutos Federais:

$\mathrm{V}$ - estimular e apoiar processos educativos que levem à geração de trabalho e renda e à emancipação do cidadão na perspectiva do desenvolvimento socioeconômico local e regional (BRASIL, 2008, não paginado).

Ainda segundo Pacheco (2009), os Institutos Federais buscam agregar formação acadêmica e preparação para o trabalho, com a proposta de uma formação que articule trabalho, ciência e cultura na perspectiva da emancipação humana.

Atualmente, segundo o MEC, são 38 Institutos Federais, 22 Escolas Técnicas vinculadas à Universidade, 2 Centros Federais de Educação Técnica, 1 Universidade Tecnológica e o Colégio Pedro II - estruturas distribuídas em todos os Estados do Brasil. Como se pode perceber, no mapa abaixo, a Rede Federal está presente em todas as unidades federativas.

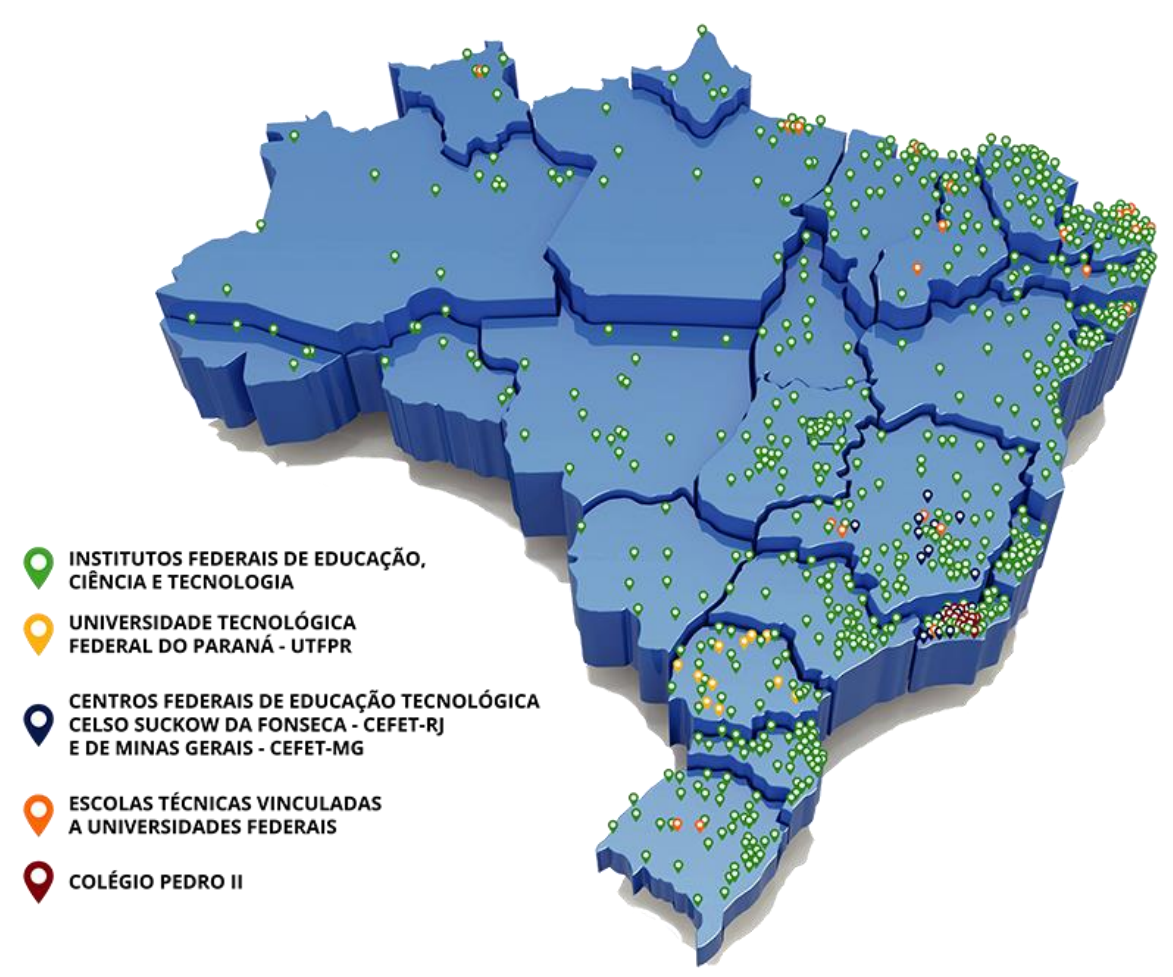

Figura 1 - Mapa de localização da Rede Federal no território brasileiro Fonte: MEC (2018).

Os Institutos Federais são pluricurriculares e multicampi, dirigidos por meio de Reitorias. São ligados à Secretaria de Educação Profissional e Tecnológica e, como última instância, ao Ministério da Educação, segundo o qual, em 2019, os números da Rede Federal permanecem os mesmos, sendo 661 unidades espalhadas por todo o País. 


\subsection{Um recorte: Instituto Federal de Educação, Ciência e Tecnologia de Minas Gerais (IFMG)}

O Instituto Federal de Minas Gerais é uma dessas instituições integrantes da Rede Federal de Educação Profissional, Científica e Tecnológica. Iniciou sua história fundindo os já tradicionais CEFETs de Ouro Preto e Bambuí e a Escola Agrotécnica Federal de São João Evangelista, além das unidades fora de sede nas cidades de Congonhas e Formiga.

Ainda em 2009, funda-se o Campus Governador Valadares; em 2010, a região metropolitana de Belo Horizonte ganha três novos campi: Betim, Sabará e Ribeirão das Neves; 2011 foi a vez da cidade de Ouro Branco. Já em 2014, mais um grande salto, com a criação de quatro novas unidades: Piumhi, Ponte Nova, Itabirito e Santa Luzia. O ano de 2015 marca a fundação do Campus Conselheiro Lafaiete e o Polo de Inovação em Formiga; em 2016, duas novas unidades: Ipatinga e Arcos. E, por último, a mais recente criação: em 2018, o Campus Ibirité inicia suas atividades de ensino. Dessa forma, atualmente, o IFMG é composto por 18 campi, sendo seis deles avançados, o Polo de Inovação, na cidade de Formiga, e uma Reitoria, com sede em Belo Horizonte.

Em números, segundo informações oficiais do IFMG, tem cerca de 16.800 alunos matriculados, divididos em 192 cursos nas diversas modalidades de Formação Inicial e Continuada, Ensino Técnico (integrado ao Ensino Médio, Concomitante, Subsequente), Ensino Superior (Bacharelado, Licenciatura e Tecnologia) e Pós-Graduação Stricto e Lato Sensu. O número de servidores está torno de 1.900, entre docentes e técnicos administrativos.

Vale ressaltar que, em Minas Gerais, a Rede Federal é composta, além do IFMG, pelo Instituto Federal do Sul de Minas, Instituto Federal do Sudeste de Minas, Instituto Federal do Norte de Minas e CEFET- MG.

O IFMG tem como missão institucional: "ofertar ensino, pesquisa e extensão de qualidade em diferentes níveis e modalidades, focando na formação cidadã e no desenvolvimento regional." E, como valores, "Ética, Transparência, Inovação e Empreendedorismo, Diversidade, Inclusão, Qualidade do Ensino, Respeito, Sustentabilidade, Formação Profissional e Humanitária, Valorização das Pessoas", traduzindo, em sua missão e valores, o que preconiza a Lei de criação dos Institutos, de alinhamento da formação para o trabalho e a formação humana.

\section{CONCLUSÃO}


O percurso e os desdobramentos históricos apontados neste levantamento vêm demonstrando como a educação técnica, ao longo das décadas, passou por várias mudanças e adequações legais. Em alguns momentos, dava-se a impressão de que a modalidade avançaria, como no contexto da ditadura, em que o anseio pelo desenvolvimento econômico e tecnológico do País dominava. Em outros, passou-se por um claro desmonte, como nos anos 1990, a despeito de uma política educacional em nível nacional, o que só foi se concretizar no fim da primeira década dos anos 2000.

Mas uma questão é comum nesta trajetória da modalidade: a dualidade da formação de mão de obra e a formação integral. Desde o início, as primeiras escolas de educação técnica e profissional, no Brasil, tiveram caráter de uma educação tecnicista, com bases na formação fragmentada e adaptativa aos interesses mercadológicos.

Destaca-se como uma grande "virada de mesa", no contexto da política educacional técnica, a criação dos Institutos Federais em 2008, que não se propõe em uma ampliação apenas numérica das instituições, mas da própria semântica e da proposta para a educação técnica. E até o momento histórico, tratado no artigo, a criação dos Institutos é a proposta que mais se aproxima do projeto societário que se volta à formação integral, omnilateral e bases unitárias. Segundo Pacheco (2009), é uma perspectiva que traz a formação humana, cidadã, antes da qualificação para o trabalho, baseada na educação oferecida na integração entre ciência, tecnologia e cultura, de forma indissociada da vida.

Pode-se afirmar que, pela primeira vez no País, ousou-se pensar uma educação que supere essa dualidade histórica, buscando alinhar uma formação para o mundo do trabalho e formação cidadã, ou seja, que vê o ser humano de forma integral.

O IFMG compõe a Rede, traduzindo em sua missão a pretensão de uma formação integral. Cresceu de maneira significativa e vem fortalecendo sua marca,por meio da qual se estabeleceu e se apresenta, para muitos, como uma possibilidade real de acesso à educação.

Uma questão certamente surge e cabe destacar - que a pretensão do artigo não é, nem de longe, romantizar ou superlativizar o modelo dos Institutos Federais, como se tudo que pretende a legislação de fato está na prática, ou mesmo que a legislação seja perfeita. Há muito que se avançar, muito que caminhar nesta proposta de educação integral, tanto na integração dos currículos dos cursos, como no próprio entendimento dos atores envolvidos no processo: servidores, gestores e estudantes. O que se buscou destacar foi a importância dos novos princípios norteadores trazidos pela criação dos Institutos Federais,associados aos propósitos de fortalecimento da educação, vindos de maneira inovadora na formação de profissionais e cidadãos. 


\title{
FROM LICEUS TO FEDERAL INSTITUTES: 110 YEARS OF FEDERAL NETWORK HISTORY
}

\begin{abstract}
The article aims to make a historical course, demonstrating the path of technical education in Brazil throughout the various moments and governments of the country, aligning the relevant laws and legal actions of this modality.This route began in slave-like Brazil, passing through the Lyceums, the first federal level technical education institutions, until the creation of the Federal Institutes in 2008, when through their creation, for the first time in the history of Brazil, The intention is for a technical education that aims at integral formation, which surpasses the historical marks brought by the modality, such as a fragmented education, purely technical and simply aimed at meeting market interests, having been deprecated to the place of a minor education. Therefore, the Federal Institutes, which make up the Federal Network of Technological Education, stood out as the great change in perspective regarding technical and vocational education. A brief overview of the development of this Network in its 10 years of history was presented, and finally a clipping at the Federal Institute of Education and Technology of Minas Gerais (IFMG), showing the campuses created and their development. For the realization of the article a qualitative methodology was used, a documental analysis based on official documents and pertinent legislation at each historical moment. A literature review was also produced, using the various authors that address the theme. The results show that education as a project in dispute, and more specifically vocational education, suffers the intersections both in its daily life and in legal areas, the article has historically pointed out these developments.
\end{abstract}

Keywords: Technical and professional education. Historic. Federal Institutes.

\section{REFERÊNCIAS}

BIAGINI, Jussara. Revisitando momentos da história do ensino técnico. 2001. Disponível em: http://www.ufop.br/ichs/conifes/anais/EDU/edu1713.htm. Acesso em: 10 abr. 2019.

BRASIL. Ministério da Educação. Expansão da Rede Federal. 2018. Disponível em: http://portal.mec.gov.br/setec-programas-e-acoes/expansao-da-rede-federal. Acesso em: 10 abr. 2019.

BRASIL. Presidência da República. Lei N. 1.606, de 29 de dezembro de 1906. Crêa nas capitães dos Estados da Republica Escolas de Aprendizes Artifices, para o ensino profissional primário e gratuito. Decreto N. 7.566, de 23 de setembro de 1909. Disponível em: http://portal.mec.gov.br/setec/arquivos/pdf3/decreto_7566_1909.pdf. Acesso em: 09 maio. 2019.

BRASIL. Presidência da República. Decreto-Lei N. 4.073, de 30 de janeiro de 1942. Lei orgânica do ensino industrial. 1942a. Disponível em:

http://www.planalto.gov.br/ccivil_03/Decreto-Lei/1937-1946/Del4073.htm. Acesso em: 06 mar. 2019. 
BRASIL. Presidência da República. Decreto N. 4.127, de 25 de fevereiro de 1942. Estabelece as bases de organização da rede federal de estabelecimentos de ensino industrial. 1942b. Disponível em: http://www2.camara.leg.br/legin/fed/declei/1940-1949/decreto-lei4127-25-fevereiro-1942-414123-publicacaooriginal-1-pe.html. Acesso em: 06 mar. 2019.

BRASIL. Presidência da República. Lei N· 3.552, de 16 de fevereiro de 1959. Dispõe sobre nova organização escolar e administrativa dos estabelecimentos de ensino industrial do Ministério da Educação e Cultura, e dá outras providências. Disponível em: http://www.planalto.gov.br/CCIVIL_03/leis/L3552.htm. Acesso em: 19 maio. 2019.

BRASIL. Presidência da República. Lei N. 4.024, de 20 de dezembro de 1961. Fixa as Diretrizes e Bases da Educação Nacional. 1961b.Disponível em: http://www.planalto.gov.br/CCIVIL_03/leis/L4024.htm. Acesso em: 09 mar. 2019.

BRASIL. Presidência da República. Lei N· 5.692, de 11 de agosto de 1971. Fixa Diretrizes e Bases para o Ensino de $1^{\circ}$ e $2^{\circ}$ Graus, e dá outras Providências. Disponível em: http://www.planalto.gov.br/ccivil_03/leis/L5692.htm. Acesso em: 15 mar. 2019.

BRASIL. Presidência da República. Lei N. 11.892 de 29 de dezembro de 2008. Institui a Rede Federal de Educação Profissional, Científica e Tecnológica, cria os Institutos Federais de Educação, Ciência e Tecnologia, e dá outras providências. Disponível em: http://www.planalto.gov.br/ccivil_03/_ato2007-2010/2008/lei/111892.htm. Acesso em: 09maio. 2019.

BRASIL. Presidência da República. Decreto-Lei N. 547, de 18 de abril de 1969. Autoriza a organização e o funcionamento de cursos profissionais superiores de curta duração. Disponível em: http://www.planalto.gov.br/ccivil_03/decreto-lei/1965-1988/Del0547.htm. Acesso em: 13 abr. 2019.

BRASIL. Presidência da República. Lei N. 6.545 de 30 de junho de 1978. Dispõe sobre a transformação das Escolas Técnicas Federais de Minas Gerais, do Paraná e Celso Suckow da Fonseca em Centros Federais de Educação Tecnológica e dá outras providências. Disponível em: http://www.planalto.gov.br/ccivil_03/LEIS/L6545.htm. Acesso em: 15 mar. 2019.

BRASIL. Presidência da República. Lei N. 9.394, de 20 de dezembro de 1996. Lei de Diretrizes e Bases da Educação Nacional Estabelece as diretrizes e bases da educação nacional. Disponível em: http://portal.mec.gov.br/arquivos/pdf/ldb.pdf. Acesso em: 15 mar. 2019.

BRASIL. Presidência da República. Lei N. 8.948 de 8 de dezembro de 1994. Dispõe sobre a instituição do Sistema Nacional de Educação Tecnológica e dá outras providências. Disponível em: http://www.planalto.gov.br/ccivil_03/LEIS/L8948.htm. Acesso em: 03 mar. 2019.

BRASIL. Presidência da República. Lei N. 3.864-A, de 24 de janeiro de 1961. Cria as Escolas Agrícolas de Bambuí e Cuiabá, nos Estados de Minas Gerais e Mato Grosso, e uma Escola de Engenharia em Uberlândia, Minas Gerais. 1961a. Disponível em: http://www.planalto.gov.br/ccivil_03/leis/1950-1969/L3864-A.htm. Acesso em: 15 mar. 2019. 
BRASIL. Presidência da República. Decreto N. 63.923, de 30 de dezembro de 1968. Eleva à categoria de Colégio o Ginásio Agrícola de Bambuí, no Estado de Minas Gerais. 1968. Disponível em: http://www2.camara.leg.br/legin/fed/decret/1960-1969/decreto-63923-30dezembro-1968-405341-publicacaooriginal-1-pe.html. Acesso em: 8 abr. 2019.

BRASIL. Presidência da República. Decreto N. 83.935, de 4 de setembro de 1979.

Disponível em: http://www2.camara.leg.br/legin/fed/decret/1970-1979/decreto-83935-4setembro-1979-433451-publicacaooriginal-1-pe.html. Acesso em: 9 abr. 2019.

BRASIL. Presidência da República. Decreto N. 87.310, de 21 de Junho de 1982.

Regulamenta a Lei ${ }^{\circ}$ 6.545, de 30 de junho de 1978, e dá outras providências. Diário Oficial [da] União - Seção 1 - 23/6/1982, Página 11496. Disponível em:

http://www2.camara.leg.br/legin/fed/decret/1980-1987/decreto-87310-21-junho-1982-

436668-publicacaooriginal-1-pe.html. Acesso em: 11 mar. 2019.

BRASIL. Presidência da República. Lei No 11.195 de 18 de novembro de 2005. Disponível em: http://www.planalto.gov.br/ccivil_03/_Ato2004-2006/2005/Lei/L11195.htm. Acesso em: 03 mar. 2019.

CUNHA, Luiz Antônio. O ensino industrial-manufatureiro no Brasil. Revista Brasileira de Educação, Rio de Janeiro, n. 14, p. 89-107, 2000. Disponível em:

http://www.scielo.br/pdf/rbedu/n14/n14a06. Acesso em: 01 mar. 2019.

CURY, Carlos Roberto Jamil; TAMBINI, Maria Ignez Saad Bedran e SALGADO, Maria Umbelina Caiafa. A profissionalização do ensino na Lei no 5692/71. Brasília: Inep, 1982.

FRIGOTTO, Gaudêncio. Os Institutos Federais de Educação, Ciência e Tecnologia e sua Relação com o Ensino Médio Integrado e o Projeto Societário de Desenvolvimento (2003-2014). Rio de Janeiro, Conselho Nacional de Desenvolvimento Científico e Tecnológico (CNPq), Fundação de Amparo à Pesquisa do Rio de Janeiro (FAPERJ), 2016. 444 p. Disponível em: https://www.academia.edu/37753809/Institutos_Federais_de_Educa\%C3\%A7\%C3\%A3o_Ci \%C3\%AAncia_e_Tecnologia_rela\%C3\%A7\%C3\%A3o_com_o_ensino_m\%C3\%A9dio_inte grado_e_o_projeto_societ\%C3\%A1rio_de_desenvolvimento. Acesso em: 10 mar. 2019.

KUENZER, Acácia Zeneida. Ensino de $2^{\circ}$ grau: o trabalho como princípio educativo. 2. ed. São Paulo: Cortez, 1992. 166 p.

NEVES, Lúcia Maria Wanderley; PRONKO, Marcela Alejandra. O mercado do conhecimento e o conhecimento para o mercado: da formação para o trabalho complexo no Brasil contemporâneo. Rio de Janeiro: EPSJV, 2008. 204 p.

MARTINS, Marcos Francisco. Ensino técnico e globalização: cidadania ou submissão? Campinas: Autores Associados, 2000.

MINAS GERAIS. Instituto Federal. Histórico. 2019. Disponível em: https://www.ifmg.edu.br/portal/sobre-o-ifmg/historico-e-missao. Acesso em: 10 maio 2019. PACHECO, Eliezer. Institutos Federais Lei 11.892 de 29/11/2008: comentários e reflexões. Natal: IFRN, 2009. 
RAMOS, Marise Nogueira. História e política da educação profissional. Curitiba: Instituto Federal do Paraná, 2014. (Coleção formação pedagógica; v. 5).

ROMANELLI, Otaíza de O. História da educação no Brasil. Rio de Janeiro: Vozes, 1983. $267 \mathrm{p}$.

SAVIANI, Dermeval. Trabalho e educação: fundamentos ontológicos e históricos. Revista Brasileira de Educação. Rio de Janeiro, v. 12, n. 34, p. 152-180, 2007. Disponível em: http://www.scielo.br/pdf/rbedu/v12n34/a12v1234.pdf. Acesso em 13 de maio 2019.

SILVA, Jackson Ronie Sá, ALMEIDA, Cristóvão Domingos de, GUINDANI, Joel Felipe. Pesquisa documental: pistas teóricas e metodológicas. Revista Brasileira de História \& Ciências Sociais, Rio Grande. , v. 1, n.1, p. 1-15, 2009. Disponível em: https://www.rbhcs.com/rbhcs/article/view/6. Acesso em: 14 maio 2019.

\section{DADOS DOS AUTORES}

\section{Ana Kelly Arantes}

Currículo Lattes: http://lattes.cnpq.br/7287063410196349

E-mail: ana.arantes@ifmg.edu.br; anakarantes@gmail.com

Doutoranda em Educação pela Universidade Federal do Espírito Santo (UFES), linha de pesquisa em Educação, Formação Humana e Políticas Públicas. Mestrado em Desenvolvimento Regional pela Universidade Estadual de Minas Gerais (UEMG) Unidade Divinópolis, linha de pesquisa Desenvolvimento Regional e Inclusão Social. Graduação em Serviço Social pela Pontifícia Universidade Católica de Minas Gerais (PUC MG).

\section{Márcia Helena Batista Corrêa Costa}

Currículo Lattes: http://lattes.cnpq.br/1487096443430384

E-mail: marcia.hbl@hotmail.com

Doutorado em Ciências Sociais pela Universidade de Campinas (UNICAMP), cuja pesquisa teve como tema planejamento urbano participativo, o caso do Conselho de Política Urbana de Belo Horizonte. Coordenou pesquisa sobre esse tema, financiada pela Fundação de Amparo à Pesquisa de Minas Gerais (FAPEMIG), analisando a revisão de plano diretor em cidade de médio porte. Foi Coordenadora da Frente Reassentamentos Urbanos do Programa Internacional de Pesquisa Cidade e Alteridade, com financiamento da FAPEMIG, programa que investiga as formas de efetivação do direito à cidade. Mestrado em Ciências Sociais pela Universidade Católica de Minas Gerais (PUC MG). Atualmente, é professora e pesquisadora da Universidade do Estado de Minas Gerais (UEMG), onde atuou no Programa de Mestrado em Desenvolvimento Regional e foi Coordenadora da Extensão Universitária (2014-2017). Orienta pesquisas sobre gestão de políticas públicas em diversas áreas, em especial, em educação e assistência social. Atualmente coordena pesquisa e extensão sobre Segurança Alimentar e Nutricional Sustentável, tendo sido financiada pesquisa pelo Conselho Nacional de Desenvolvimento Científico e Tecnológico (CNPq), em parceria internacional com a Food and Agriculture Organization of the United Nations (FAO) e com o Centro Universitario de Excelencia en Agroecología y Saberes Locales da Universidad Mayor de San Simón da Bolívia. 